\title{
WHO releases guidelines for treating chemical warfare victims after possible Syria attacks
}

$\mathrm{T}$ he World Health Organization (WHO) has released guidelines on treating patients exposed to deadly chemicals within days of reports of possible chemical weapons attacks in Syria.

The interim WHO document, released Aug. 27, guides health workers on the identification, triage, decontamination and treatment of "chemicallycontaminated" patients.

Médecins Sans Frontières (MSF) states in an Aug. 24 media release that some 3600 patients, reportedly with symptoms of exposure to chemical warfare agents, were admitted to three Damascus-area hospitals on Aug. 21. They had neurotoxic symptoms including convulsions, excess saliva, pinpoint pupils, blurred vision and respiratory disease. Of those patients, 355 reportedly died.

WHO's new guidance advises such symptoms may indicate exposure to nerve agents, such as sarin or VX gas - both reportedly weapons in Syria's arsenal.

MSF can neither confirm the exact cause of the symptoms nor establish who is responsible for the attack; however, the epidemiological pattern of events - including the massive influx of patients in a short period of time and contamination of first responders strongly indicates mass exposure to a neurotoxic agent, Director of Operations Dr. Bart Janssens said in a news release.

Patients were treated using atropine, a drug recommended in the guidelines for the initial treatment of exposure to nerve agents. MSF is now trying to restock the hospitals' supplies, and has sent 7000 vials of atropine to supplement the 1600 supplied in recent months.

While there is currently "no con firmation that there has been an incident involving chemical weapons" in Syria, WHO Communications Officer Glenn Thomas said in an email, "the
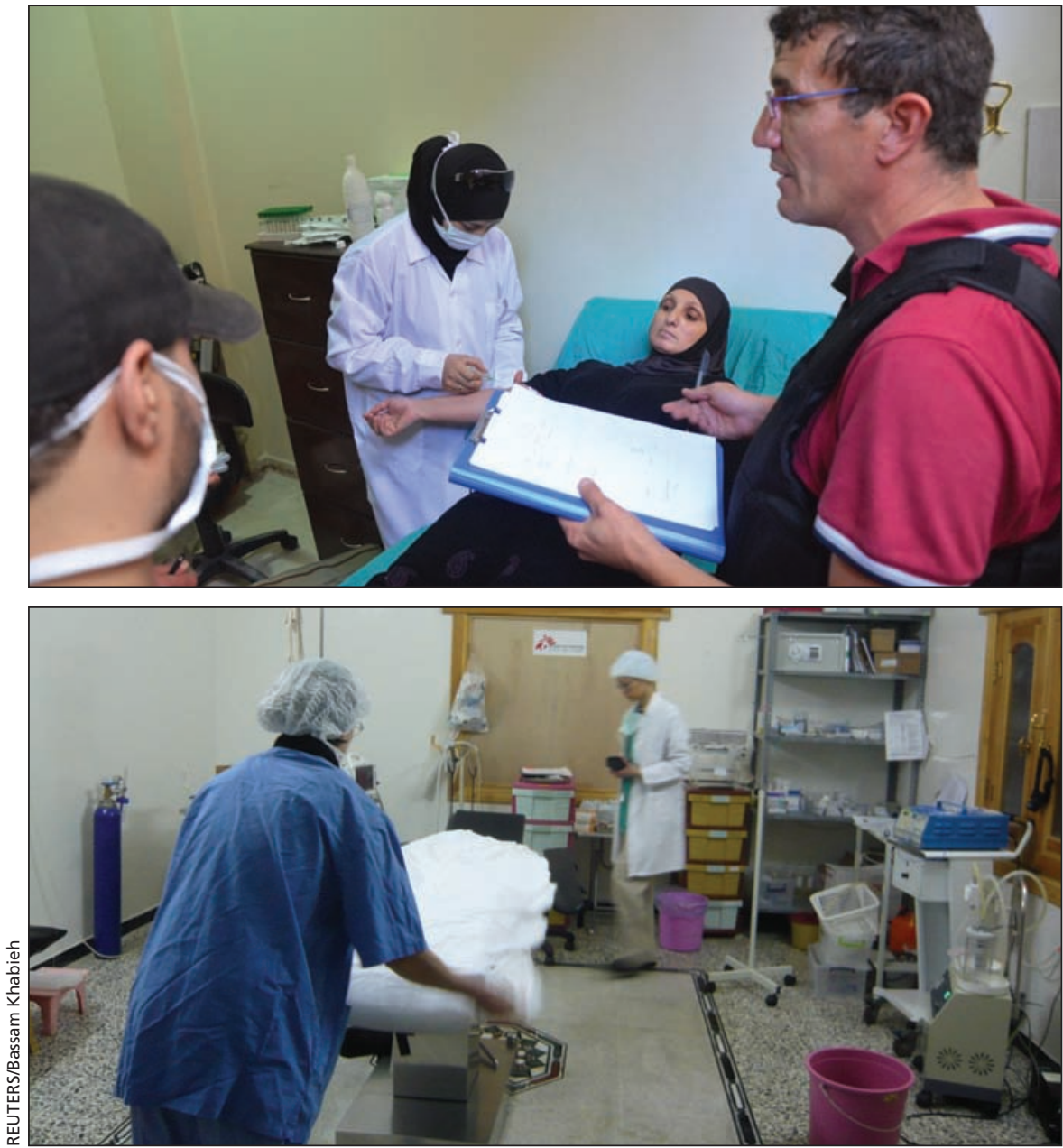

A United Nations weapons expert meets a woman affected by an apparent gas attack as she is being treated at a hospital in Zamalka, a suburb of Damascus, Syria, on Aug. 28.

guidance provides practical and useful information" for response to chemical contamination scenarios "that are not only specific to Syria."

This includes flowcharts to help first responders care for those exposed to deadly chemicals, as well as recommendations for personal protection.

The interim guidelines, which expire Oct. 31, "will be further reviewed and updated as greater understanding of current risks evolve," WHO Communications Officer Tarik Jasarevic said in an email.

A United Nations probe into the possible use of chemical warfare in Syria will leave the country on Aug. 31, one day ahead of schedule, fuelling speculation about the threat of air strikes from the United States and United Kingdom.

MSF released a statement Aug. 28 categorically rejecting that the humanitarian organization's report be used as "justification for military action," stating that "scientific confirmation of the toxic agent" is still required. - Lauren Vogel, CMAJ

CMAJ 2013. DOI:10.1503/cmaj.109-4592 